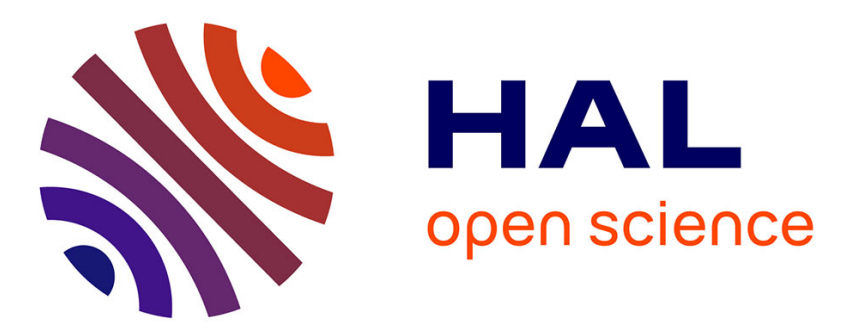

\title{
Multiscale estimation of the viscoelastic properties of cementitious materials at early age a combined analytical and numerical approach
}

\author{
T. Honorio, B. Bary, F. Benboundjema
}

\section{- To cite this version:}

T. Honorio, B. Bary, F. Benboundjema. Multiscale estimation of the viscoelastic properties of cementitious materials at early age a combined analytical and numerical approach. CONCREEP 10 Mechanics and Physics of Creep, Shrinkage, and Durability of Concrete and Concrete Structures, Sep 2015, Vienne, Austria. cea-02500839

HAL Id: cea-02500839

https://hal-cea.archives-ouvertes.fr/cea-02500839

Submitted on 6 Mar 2020

HAL is a multi-disciplinary open access archive for the deposit and dissemination of scientific research documents, whether they are published or not. The documents may come from teaching and research institutions in France or abroad, or from public or private research centers.
L'archive ouverte pluridisciplinaire HAL, est destinée au dépôt et à la diffusion de documents scientifiques de niveau recherche, publiés ou non, émanant des établissements d'enseignement et de recherche français ou étrangers, des laboratoires publics ou privés. 


\title{
Multiscale estimation of the viscoelastic properties of cementitious materials at early age: a combined analytical and numerical approach
}

\author{
T. Honorio ${ }^{1,2}$; B. Bary ${ }^{1}$ and F. Benboudjema ${ }^{2}$ \\ ${ }^{1}$ CEA, DEN, DPC, SECR, Laboratoire d'Etude du Comportement des Bétons et des \\ Argiles, F-91191 Gif-sur-Yvette, France; email: tulio.honoriodefaria@cea.fr \\ ${ }^{2}$ LMT (ENS Cachan, CNRS, Université Paris Saclay) 94235 Cachan, France
}

\begin{abstract}
We propose an investigation combining numerical and analytical tools to estimate the ageing viscoelastic properties of cementitious materials within a multiscale framework. With analytical homogenization the properties at the cement paste and mortar scale are estimated by a combination of Generalized Self-Consistent (GSC) and Mori-Tanaka (MT) schemes. With numerical homogenization the effective properties at the concrete scale are estimated. Numerical homogenization has the advantage of allowing to assess local information as well as to study more complex geometries. This combined strategy constitutes a promising tool to investigate how different mechanisms leading to ageing at the hydrate products scale, as well as other features of cement-based materials such as the Interfacial Transition Zone (ITZ), affect the viscoelastic behavior at superior scales. In this context, we study the solidification of non-ageing constituents as the mechanisms leading to the ageing behavior. Relaxation and creep results at different scales are presented.
\end{abstract}

\section{INTRODUCTION}

Homogenization techniques have been widely used to estimate different properties of concrete. The estimation of elastic properties is of current use, and due to the Mandel (1966) correspondence principle, the estimation in non-ageing viscoelasticity is straightforward. More recent investigations have dealt with the ageing cases in which Mandel correspondence principle does not hold anymore (Masson et al. 2012; Sanahuja 2013a; Scheiner and Hellmich 2009). Different mechanisms are reported as potentially leading to the ageing behavior (Carol and Bažant 1993; Thomas and Jennings 2006; Vandamme and Ulm 2009). Moreover, other features of cement-based materials, such as the presence of an ITZ and the mismatch of properties of different phases may affect the overall response.

We propose an investigation combining numerical and analytical tools to estimate the ageing viscoelastic properties of cementitious materials within a multiscale framework. We are interested in the behavior at the mesoscale, defined here as the concrete (or coarse aggregate) scale but without neglecting the multiscale character of cement-based materials, especially some relevant aspects of some phases at the lower scales, such as, for instance, solidification or phases with viscoelastic 
behavior. Some details of the analytical and numerical analysis are presented in the following. This work is a contribution towards the development of tools to investigate the mechanisms leading to ageing and how they affect the macroscopic response of the material.

\section{ANALYTICAL HOMOGENIZATION}

Analytical homogenization is used to estimate the properties at the cement paste and mortar scale (Figure 1). Two-coated sphere morphology is used to represent the cement paste and mortar microstructures, as proposed e.g. by Stora et al. (2009). Regarding the cement paste, the hydrating particle is embedded in a high density products layer which is, in turn, embedded in a low density products layer. Regarding the mortar, the sand particle is embedded in an ITZ layer which is, in turn, embedded in a cement paste layer. The GSC scheme is used to obtain the homogenized properties of the cement paste and mortar. MT scheme is used to estimate the properties within each coat. This representation of the microstructure was recently applied by the authors to estimate the elastic properties of concrete (Honorio et al. 2014). Here, both homogenization schemes are developed in an ageing viscoelastic framework, based on the derivation by Sanahuja (2013) for the MT scheme and on a specific formulation developed by the authors for the GSC (Honorio et al. submitted paper). These schemes are derived in a division algebra in which the noncommutative Volterra integral operator is defined. The resulting lengthy equations are not presented here for conciseness. As in Sanahuja (2013), a numerical solution following Bažant (1972) proposition is used to compute the time integrals.

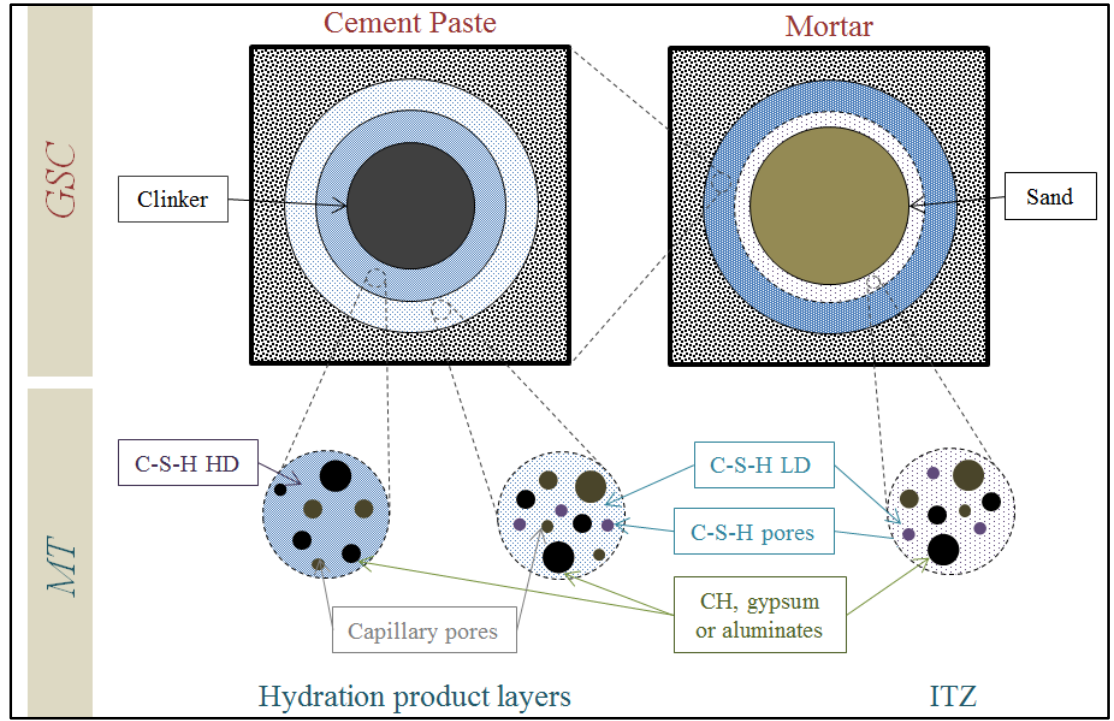

(a)

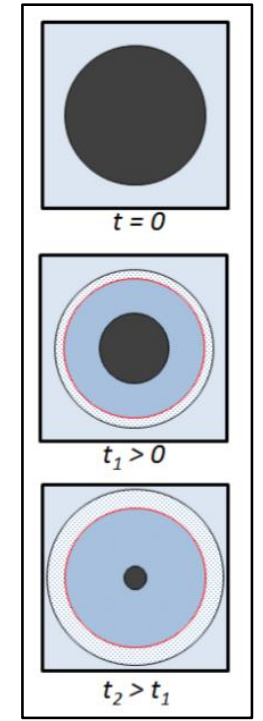

(b)

Figure 1. Microstructure representation (a) and solidification mechanism (b)

\section{Precipitation/solidification mechanism}

For the analytical part, we propose a scenario in which solidification of a nonageing phase lead to the ageing behavior (Carol and Bažant 1993). Other scenarios in 
which, for example, an intrinsically ageing phase undergoes solidification will be studied in a future contribution. Solidification is represented following Carol and Bažant (1993) solidification theory defined in a tensorial form (Sanahuja 2013b), which allows writing the relaxation tensor for a given phase solidifying at time $t^{\prime}$ by:

$$
\mathbb{R}_{i}\left(t, t^{\prime}\right)=\mathbb{R}_{s}\left(t-t^{\prime}\right) \mathrm{H}\left(t^{\prime}-t_{i}\right)
$$

where $\mathrm{H}($.$) is the Heaviside function and \mathbb{R}_{S}\left(t-t^{\prime}\right)$ is the relaxation tensor of the solidified material. We adopted Maxwell rheological model to write $\mathbb{R}_{S}\left(t-t^{\prime}\right)$.

An ageing function is attributed to each phase present in the paste according to the hydration kinetics model of cement proposed by Honorio et al. (submitted paper). The evolution of volume fractions, as presented in Figure 2, is estimated by means of Tennis and Jennings (2000) balance equations. A non-ageing viscoelastic behavior is attributed to $\mathrm{C}-\mathrm{S}-\mathrm{H}$ phases; the other phases are assumed to behave elastically. In this paper the C-S-H behaviors are represented by Maxwell generalized rheological model with the parameters presented in Table 1. Such a behavior seems adequate regarding the effective behavior obtained confronted to experimental data. However, further investigations are needed to define $\mathrm{C}-\mathrm{S}-\mathrm{H}$ behavior at early-age. The elastic properties of the phases are the same as in Honorio et al. (2014). The repartition of the products in High Density (HD) and Low Density layers and in ITZ is performed following also Honorio et al. (2014).

\section{Estimation of mortar properties}

ITZ volume and composition are established as in Honorio et al. (2014). Differently of the cement paste scale, the volumes of the three phases in the coated sphere morphology at the mortar scale remain the same.
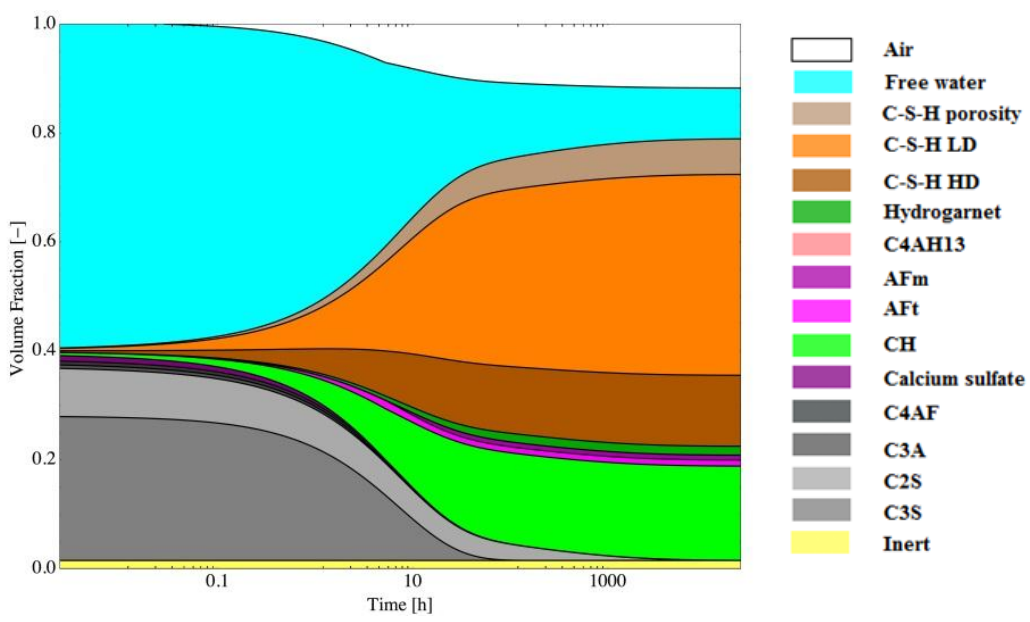

Figure 2. Evolution of volume fractions of hydration products and reactants

Table 1. Behavior of C-S-H for the shear and bulk modulus based on Maxwell generalized model: $\chi=\chi_{0}+\sum \chi_{i} \exp \left[-\left(t-t^{\prime}\right) / \tau_{i}\right]$

\begin{tabular}{|l|c|c|c|c|c|c|c|c|c|}
\hline & $\begin{array}{c}\boldsymbol{E} \\
{[\mathbf{G P a} \text { ] }}\end{array}$ & $\boldsymbol{v}$ & $\begin{array}{c}\boldsymbol{\tau}_{1} \\
\text { [days] }\end{array}$ & $\begin{array}{c}\boldsymbol{\tau}_{2} \\
\text { [days] }\end{array}$ & $\begin{array}{c}\boldsymbol{\tau}_{3} \\
\text { [days] }\end{array}$ & $\chi_{0}$ & $\chi_{1}$ & $\chi_{3}$ & $\chi_{4}$ \\
\hline LD & 29.4 & 0.24 & 0.1 & 1 & 10 & 0.2 & 0.4 & 0.2 & 0.2 \\
\hline HD & 21.7 & 0.24 & 0.1 & 1 & 10 & 0.2 & 0.4 & 0.2 & 0.2 \\
\hline
\end{tabular}




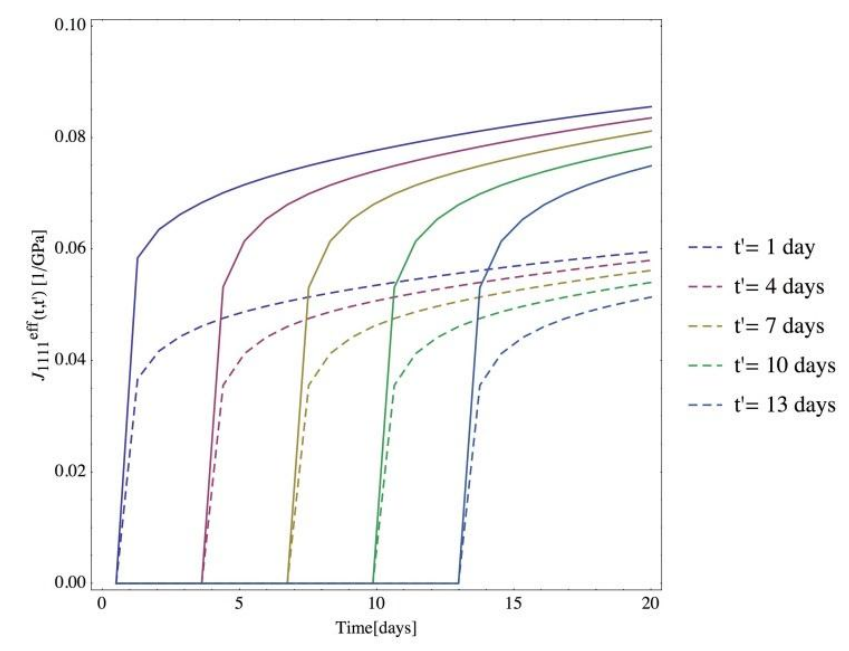

Figure 3. Creep functions (uniaxial) of cement paste (full lines) and mortar (dashed lines) estimated by analytical homogenization

\section{Results}

Bulk and shear moduli were obtained by analytical homogenization. With these properties, the compliance tensor can be computed by inversion of the stiffness tensor in the Volterra integral operator formalism. Figure 3 shows the uniaxial creep function obtained by analytical homogenization for the cement paste and mortar. With the behavior attributed to the phases, a not very well pronounced ageing character is observed at the cement paste and mortar scale. As expected, the creep in the cement paste is more accentuated than in the mortar paste, even if the ITZ creep (not shown for conciseness) is more elevated than cement paste creep.

\section{NUMERICAL HOMOGENIZATION}

Numerical homogenization is used to estimate the properties at the concrete scale. Here, we use a specific procedure associated with the Finite Elements code (Cast3m) to generate and compute 3D microstructures (de Larrard et al. 2013). With numerical homogenization, local information regarding the stresses and strains repartition in the heterogeneities and in definite regions of the matrix can be assessed. This is an advantage compared to analytical schemes which generally provide accurate estimations only on averaged fields. With the local information, the zones in which stresses are localized can be more precisely identified. Previous results showed that a considerable dispersion of the averaged stresses within the inclusions and matrix subvolumes is observed (Bary et al. 2014). Additionally, numerical homogenization allows testing more complex geometries and constitutive models.

The representative elementary volume (REV) tested is shown in Figure 4. The total volume fraction of the 556 inclusions is $40.0 \%$. The matrix is divided in 125 elements in the local evaluation. Kinetic uniform boundary condition is adopted. 

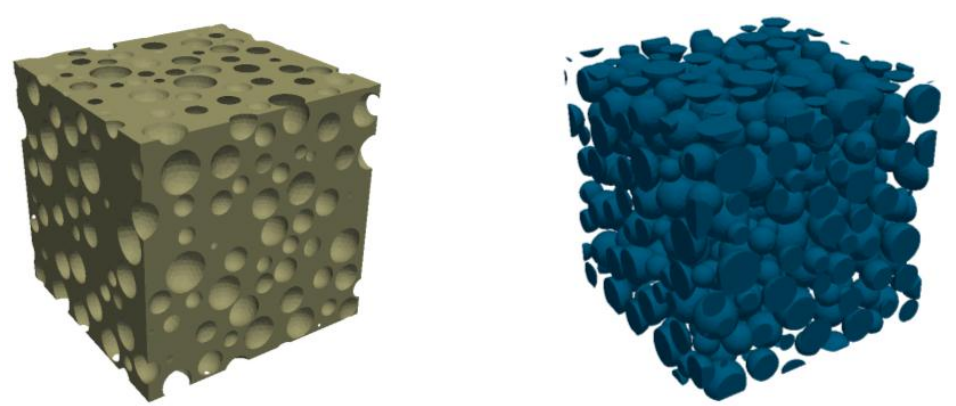

\section{Figure 4. REV with matrix (left) and spherical inclusions (right) used in FEM simulations}

\section{Results}

At the concrete scale, the behavior of the mortar is fitted on the macroscopic one obtained by analytical homogenization by means of Prony series multiplied by and ageing function. Figure 5 shows the effective creep function for concrete obtained by the numerical homogenization. With the mortar behavior computed in the last section, only a moderate ageing effect is observed in the period of the analysis.

Figure 6 shows an example of dispersion of the average strains within aggregates and matrix subvolumes for a given loading time. A more pronounced dispersion is observed within the inclusions. A part of this effect is due to the edge effects occurring in the inclusions near the boundaries where the loading is applied (Bary et al. 2014). Figure 7 shows an example of the longitudinal strain distribution in the material for two given times and a loading time of 4 days. In this figure it is possible to observe that the strains evolve differently within the matrix and the inclusions: they tend to decrease on average in the matrix while they increase in the aggregates. Further investigations are needed to study the effects of the aggregate shape on the dispersion of strains and stresses.

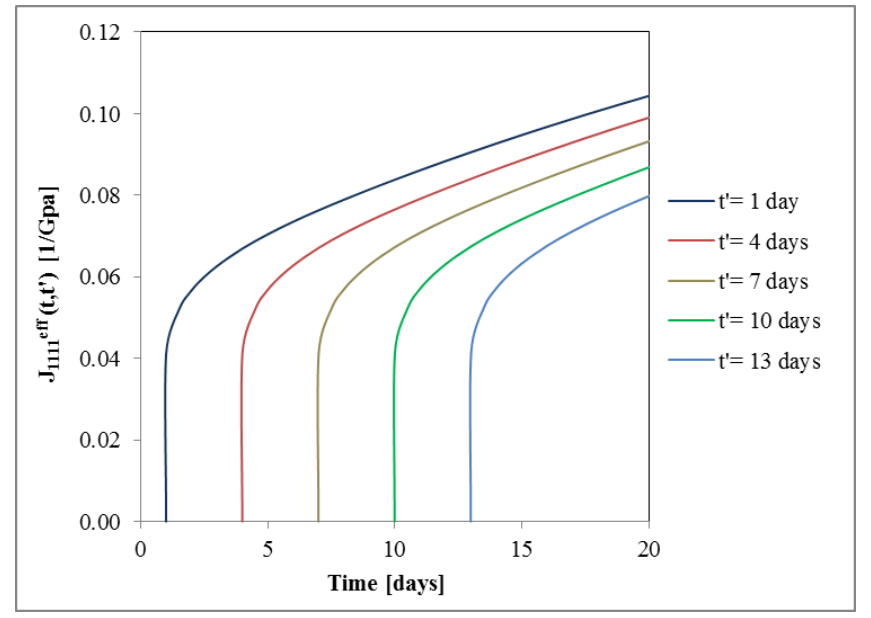

Figure 5. Overall uniaxial creep function of concrete obtained by combined numerical and analytical homogenization 

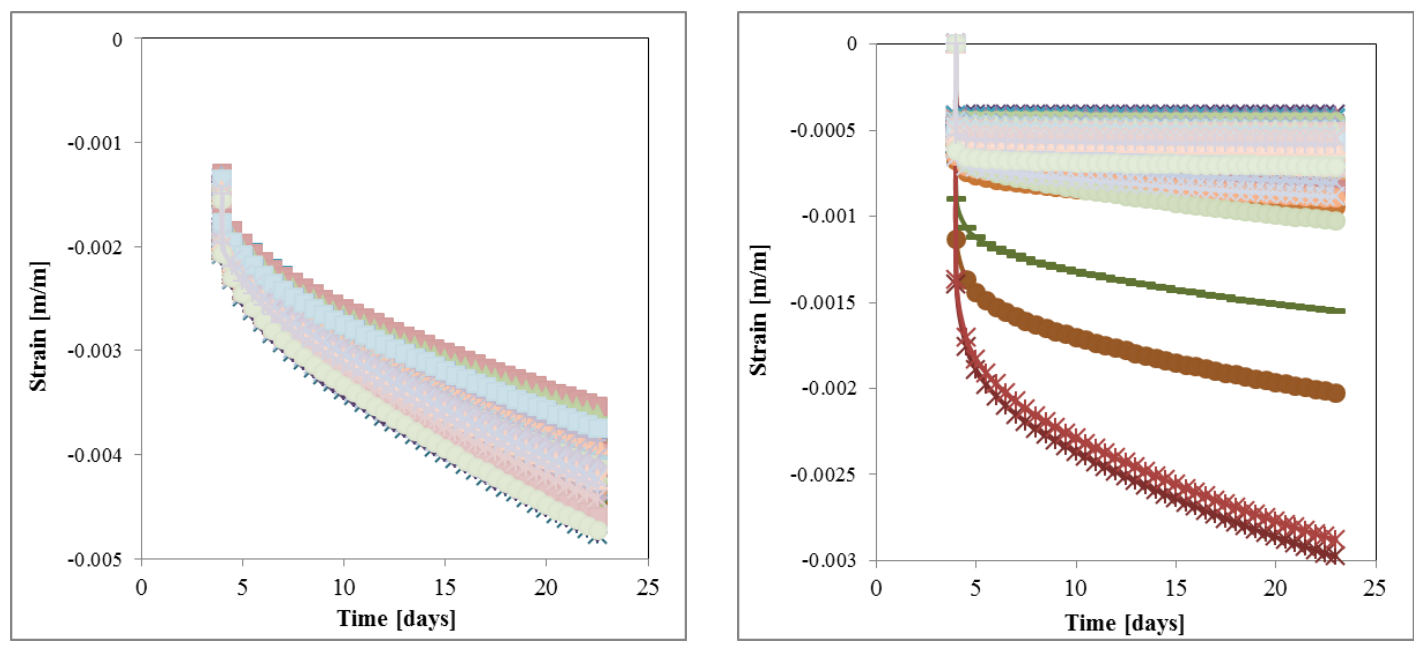

Figure 6. Dispersion of the uniaxial strain within the matrix (left) and the aggregates (right) and for $t^{\prime}=4$ days
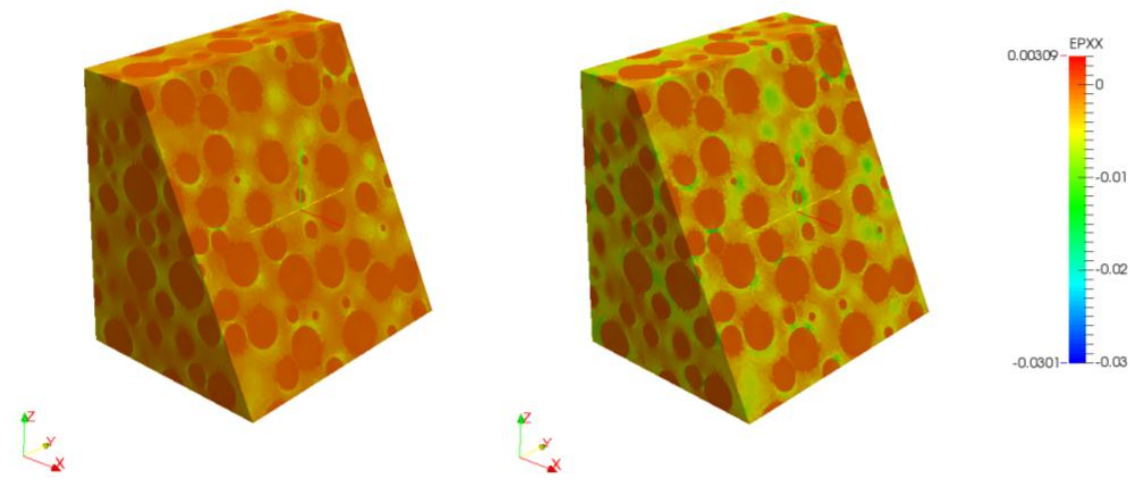

Figure 7. Strains within aggregates and mortar matrix at different ages for $t^{\prime}=4$ days: $t=6.5$ days (left); $t=20$ days (right)

\section{CONCLUSIONS AND PERSPECTIVES}

A strategy combining analytical and numerical homogenization is proposed to investigate the ageing viscoelastic behavior of cement-based materials at early-age in a multiscale framework. Analytical schemes derived in an ageing linear viscoelasticity background are used to estimate the properties at the cement paste and mortar scales. Numerical homogenization is used to study the concrete scale. This work provides a promising first attempt in the investigation of the factors affecting the ageing viscoelastic behavior. Further developments including other aspects important for early age analysis will be considered in future contributions.

- The approach develop here allows to investigate different propositions of mechanisms leading to an ageing behavior. In future communications, phases with intrinsically ageing behavior will be studied. Further developments include also an improved description of C-S-H viscoelastic behaviour (e.g. Sanahuja and Dormieux 2010; Smilauer and Bazant 2010; Vandamme and Ulm 2009). 
- The estimations of the creep response are in agreement with the usual values obtained experimentally for similar concretes. Experimental validation in a multiscale background is foreseen.

- Strategies to account for the existence of a percolation threshold are to be developed. Also an improved description of the ITZ accounting, for example, for the interpenetration of the ITZ of neighboring particles, a more precise composition of the ITZ and a definition of a fixed ITZ volume independent of the size of the particle are aspects to be considered.

- According to the homogenized behavior of the mortar, different microstructures (with spherical, Voronoi and oblate inclusions) will be studied numerically in future contributions.

\section{Acknowledgements}

This present work has been performed as part of the project on disposal of LILW-SL that is carried out by ONDRAF/NIRAS, the Belgian Agency for Radioactive Waste and enriched Fissile Materials.

\section{REFERENCES}

Bary, B., Gélébart, L., Adam, E., and Bourcier, C. (2014). "Numerical analysis of linear viscoelastic 3D concrete specimens." Computational Modelling of Concrete Structures, CRC Press, 373-381.

Bažant, Z. P. (1972). "Numerical determination of long-range stress history from strain history in concrete." Matériaux et Construction, 5(3), 135-141.

Carol, I., and Bažant, Z. (1993). "Viscoelasticity with Aging Caused by Solidification of Nonaging Constituent." Journal of Engineering Mechanics, 119(11), 22522269.

Honorio, T., Bary, B., and Benboudjema, F. (in preparation). "Effective properties of n-coated composite spheres in an ageing viscoelastic framework."

Honorio, T., Bary, B., and Benboudjema, F. (2014). "Estimation of Elastic Properties of Cement based Materials at Early Age based on a Combined Numerical and Analytical Multiscale Micromechanics Approach.” RILEM International Symposium on Concrete Modelling, Beijing, China.

Honorio, T., Bary, B., Benboudjema, F., and Poyet, S. (submitted paper). "Modelling hydration kinetics based on boundary nucleation and space-filling growth in a fixed confined zone."

De Larrard, T., Bary, B., Adam, E., and Kloss, F. (2013). "Influence of aggregate shapes on drying and carbonation phenomena in 3D concrete numerical samples." Computational Materials Science, 72, 1-14.

Mandel, J. (1966). "Cours de mécanique des milieux continus."

Masson, R., Brenner, R., and Castelnau, O. (2012). "Incremental homogenization approach for ageing viscoelastic polycrystals." Comptes Rendus Mécanique, Recent Advances in Micromechanics of Materials, 340(4-5), 378-386. 
Sanahuja, J. (2013a). "Effective behaviour of ageing linear viscoelastic composites: Homogenization approach." International Journal of Solids and Structures, 50(19), 2846-2856.

Sanahuja, J. (2013b). "Efficient Homogenization of Ageing Creep of Random Media: Application to Solidifying Cementitious Materials." American Society of Civil Engineers, 201-210.

Sanahuja, J., and Dormieux, L. (2010). "Creep of a C-S-H gel: a micromechanical approach." Anais da Academia Brasileira de Ciências, 82(1), 25-41.

Scheiner, S., and Hellmich, C. (2009). "Continuum microviscoelasticity model for aging basic creep of early-age concrete." Journal of engineering mechanics, 135(4), 307-323.

Smilauer, V., and Bazant, Z. P. (2010). "Identification of viscoelastic CSH behavior in mature cement paste by FFT-based homogenization method." Cement and Concrete Research, 40(2), 197-207.

Stora, E., Bary, B., He, Q.-C., Deville, E., and Montarnal, P. (2009). "Modelling and simulations of the chemo-mechanical behaviour of leached cement-based materials: Leaching process and induced loss of stiffness." Cement and Concrete Research, 39(9), 763-772.

Tennis, P. D., and Jennings, H. M. (2000). "A model for two types of calcium silicate hydrate in the microstructure of Portland cement pastes." Cement and Concrete Research, 30, 855-863.

Thomas, J. J., and Jennings, H. M. (2006). "A colloidal interpretation of chemical aging of the C-S-H gel and its effects on the properties of cement paste." Cement and Concrete Research, 36(1), 30-38.

Vandamme, M., and Ulm, F.-J. (2009). "Nanogranular origin of concrete creep." $P N A S$. 